\title{
Resíduos de agrotóxicos em alimentos
}

\section{Pesticide residues in food}

\author{
Agência Nacional de Vigilância Sanitária - Anvisa
}

A preocupação com a presença de agrotóxicos nos alimentos é tão antiga quanto a introdução destes produtos químicos no controle de pragas e doenças que afetam a produção agrícola. Apesar disso, somente em anos mais recentes, o avanço do conhecimento científico e as novas tecnologias da área laboratorial, vêm permitindo a avaliação da qualidade dos alimentos que chegam à mesa da população. Para o consumidor a notícia traz um alívio, afinal distinguir o alimento com nível de agrotóxicos irregular na prateleira do supermercado é praticamente impossível.

Ao longo das duas últimas décadas o monitoramento de resíduos de agrotóxicos em alimentos no Brasil foi marcado por uma série de esforços isolados de órgãos estaduais de saúde, agricultura e instituições de pesquisas. Esse fato sempre impediu que o País tivesse uma noção clara dos níveis de agrotóxicos encontrados em seus produtos agrícolas.

O passo mais significativo para resolver esse problema foi a criação do Programa de Análise de Resíduos de Agrotóxicos em Alimentos (PARA). Nos últimos quatro anos a Agência Nacional de Vigilância Sanitária (Anvisa) tem monitorando, por meio do programa, nove culturas presentes na mesa dos brasileiros. Os resultados do PARA trazem boas e más noticias. O lado positivo é que o diagnóstico sobre os níveis de agrotóxicos presentes em alimentos está chamando a atenção dos produtores e autoridades da área agrícola em relação à aplicação desses produtos. Mesmo assim, ainda é grande a quantidade de irregularidades encontradas no uso de agrotóxicos. Entre 2001 e 2004 foram analisadas 4 mil amostras de alimentos. O resultado mostrou que $28 \%$ possuíam algum problema. Entre as amostras irregulares, $83 \%$ dos desvios se referiam ao uso de produtos não autorizados para determinada cultura. Isso significa que o agricultor utilizou o agrotóxico sem orientação e sem saber qual a quantidade adequada para aquela aplicação. No restante dos casos os problemas estavam na quantidade de resíduos de agrotóxicos encontrados acima dos níveis permitidos pela legislação.

Como explica o gerente-geral de Toxicologia da Anvisa, Luiz Cláudio Meirelles, o risco dessas irregularidades para a saúde humana não é imediato, mas os danos causados pelo consumo de produtos com agrotóxicos a longo prazo precisam ser levados em consideração. "Dificilmente alguém vai comer um tomate, ou mamão, e passar mal no momento seguinte, mas o consumo de alimentos com resíduos de agrotóxicos envolve riscos que podem ser cumulativos e até desconhecidos", explica.

O esforço vem em momento oportuno. A agricultura brasileira tem se destacado com números cada vez mais expressivos, na produção, em área plantada, na exportação e na quantidade de tecnologias empregadas no campo. Tal crescimento leva também à utilização de maiores quantidades de agrotóxicos na produção agrícola, colocando o Brasil como segundo maior consumidor mundial. De forma geral, a aplicação está presente na maior parte das culturas, mas as que mais trazem preocupação são aquelas consumidas em grande quantidade pela população na forma in natura.

O registro de produtos agrotóxicos no Brasil envolve o Ministério da Agricultura e a Anvisa. O ministério é o responsável pelo registro e a Agência pela avaliação sobre a segurança dos defensivos. "Para a vigilância sanitária é indispensável o estudo sobre os riscos que os agrotóxicos podem trazer para o consumidor e o trabalhador rural", defende o diretor-presidente da Anvisa, Dirceu Raposo de Mello.

O assessor regional de toxicologia da Organização Pan-Americana de Saúde, Diego Gonzales, admite que ainda hoje há poucos dados disponíveis sobre a 
exposição a agrotóxicos. A carência de dados significa que muitos problemas associados ao uso indiscriminado desses produtos podem acabar não sendo diagnosticados.

A dificuldade em controlar os efeitos provocados pelo uso de agrotóxicos em alimentos está no fato de que essa é uma contaminação invisível. "É praticamente impossível para o consumidor reconhecer um produto que recebeu a pulverização de produtos não permitidos ou além do limite autorizado, por isso é tão importante termos um programa que faça esse controle", explica o gerente de Avaliação de Riscos da Anvisa, Ricardo Velloso.

O monitoramento de resíduos de agrotóxicos em alimentos não é um trabalho simples. Em cada uma das amostras, os laboratórios participantes do programa fazem uma busca por 92 tipos diferentes de substâncias, incluindo aquelas proibidas no País. Até hoje, já foram realizadas 368.092 análises ao custo de aproximadamente $\mathrm{R} \$ 7$ milhões. $\mathrm{O}$ valor chega a ser insignificante diante do que o mercado de agrotóxicos movimenta anualmente no Brasil: US\$ 4,2 bilhões, segundo dados de 2004. A definição dos limites de produtos aceitáveis nos alimentos é um conceito em constante mudança. Há 20 anos a falta de tecnologias mais eficientes fazia dos níveis toleráveis de agrotóxicos em alimentos uma verdadeira incógnita. Atualmente, as taxas aceitáveis são revistas a todo o momento.

De acordo com Luiz Cláudio Meirelles ainda não é possível fazer um diagnóstico geral sobre a presença de agrotóxicos em alimentos em todo o País, pois alguns estados ainda não fazem a coleta de alimentos para testes. Atualmente 16 Estados mais o Município de São Paulo participam do PARA. Mesmo assim, o programa já mostra resultados positivos, principalmente nos locais onde ele existe há mais tempo. Um exemplo é o Estado de Pernambuco. Nesse Estado a vigilância sanitária fez uma parceria com o Ministério Público estadual e as principais redes de supermercados da região. No programa, denominado de "Parinha", os fornecedores de produtos com problemas são impedidos de vender até que o desvio seja corrigido. Segundo o diretor da vigilância sanitária de Pernambuco, Jaime Brito, é preciso evitar que as irregularidades se repitam. "Todo esse trabalho está tendo uma repercussão muito boa, pois cada desvio que encontramos tem uma reação imediata", justifica. Outro caso é o de São Paulo, onde há um programa fiscal. Nesse caso os produtos irregulares são inutilizados.

A importância do monitoramento desses produtos desperta a atenção de vários setores da sociedade. O Instituto de Defesa do Consumidor é uma das instituições que defendem a rápida ampliação do programa da Anvisa para que o consumidor tenha certeza da segurança dos alimentos que leva para casa. O PARA começou a coleta de amostras em 2002 com a participação de quatro Estados, mas a meta é que todas as unidades da federação participem do programa.

Se para o consumidor o maior risco é a longo prazo, para o trabalhador rural o problema é imediato. A falta de orientação adequada também acaba deixando os agricultores menores em uma situação de maior exposição ao risco. Além de trazer problemas para a saúde do trabalhador rural, a falta de instrução correta pode gerar reflexos na mesa do consumidor. Segundo o assessor da Secretária de Agricultura Familiar do Ministério do Desenvolvimento Agrário Jean Pierre, as propriedades familiares representam $84 \%$ dos estabelecimentos rurais no País e produzem boa parte das verduras e legumes no Brasil.

A questão dos agrotóxicos é certamente uma discussão que desperta paixões. Quase todo o setor produtivo considera imprescindível a utilização dos agrotóxicos para garantir o rendimento de suas lavouras. Por outro lado os consumidores cobram cada vez mais a responsabilidade do governo na monitoração dos níveis de segurança desses produtos em alimentos. Para o diretor da Anvisa Cláudio Maierovitch é preciso estar sempre voltado para o objetivo final do trabalho da vigilância, que é a saúde da população. "Eventualmente impomos regras que geram reclamações por parte do setor produtivo, mas o trabalho de regulação torna isso necessário. O interesse coletivo maior é a segurança desses produtos". 


\section{HISTÓ RICO}

Há mais de 2 mil anos os agricultores utilizavam substâncias que prevenissem os danos causados por pragas. Um dos primeiros recursos utilizados foi o enxofre. No século XV, outras sustâncias tóxicas, como arsênico, mercúrio e chumbo, foram incorporadas no combate às pragas. Já no século XVII, o sulfato de nicotina, extraído das folhas de tabaco, também passou a ser adotada como arma contra insetos.

No Brasil, o uso de agrotóxicos industrializados já tem mais de meio século. Uma das primeiras substâncias utilizadas nas lavouras brasileiras foi o DDT, considerados um dos primeiros pesticidas modernos. A substância foi sintetizada em 1874, porém, somente no início da segunda guerra mundial é que o DDT começou a ser utilizado no combate de pragas e, especialmente, do mosquito transmissor da malária. O DDT, como todos os demais organoclorados, foram banidos dos agrotóxicos no Brasil tendo em vista os efeitos nocivos detectados após a introdução do seu uso.

\section{DENTRO DE CASA}

O problema da intoxicação por causa da aplicação inadequada de produtos tóxicos também deve ser combatido dentro de casa. Isso porque, várias substâncias utilizadas em agrotóxicos estão presentes em inseticidas domésticos. O mau-uso desses produtos pode levar a problemas imediatos como um crise respiratória ou uma intoxicação alimentar. Segundo Lia Giraldo, do Centro de Pesquisa Aggeu Magalhães (PE), há um problema de educação no uso de agrotóxicos e inseticidas domésticos. "Para lidar com esses produtos, a pessoa deveria ser no mínimo alfabetizada e treinada, mas ainda são raras as experiências de educação", enfatiza.

Lia Giraldo apresenta um dado surpreendente: proporcionalmente, o número de mortes em decorrência de asma na cidade do Recife é maior que no município de São Paulo. Apesar do clima na capital paulista ser mais favorável ao surgimento dessa doença, o grande uso de inseticidas domésticos na capital pernambucana faz com que Recife apresente uma taxa alta de mortalidade por asma. 